\title{
Między postprawdą a (pseudo)mądrością tłumu - o epistemicznej pułapce cyfrowych mediów i analogowych kompetencjach jako środkach jej uniknięcia
}

\begin{abstract}
Adam Pietrzykowski, Między post-prawda a (pseudo)mądrościa ttumu o epistemicznej pułapce cyfrowych mediów i analogowych kompetencjach jako środkach jej uniknieccia [Between post-truth and (pseudo)wisdom of the crowds - on epistemic trap of digital media and analog competences as means of avoiding it]. Interdyscyplinarne Konteksty Pedagogiki Specjalnej, nr 23, Poznań 2018. Pp. 77-91. Adam Mickiewicz University Press. ISSN 2300-391X. DOI: https://doi.org/10.14746/ikps.2018.23.04

In the modern world, truth has become an anachronistic value. At the same time, hopes associated with its restitution by the networked crowd have proved futile. The growing dominance of audiovisual media inevitably leads to the formation of a new man, driven more by affection than rationality. Phenomena such as secondary illiteracy, language depletion and the rise of populism are signs of this process. The development of media literacy suggested by theoreticians of education may be an insufficient remedy for the indicated civilization problem. The solution may be returning to basic competences shaped, in particular, by philosophical education, which may become the proper medium for restoring critical reason in society.
\end{abstract}

KEY WORDS: media, epistemic crisis, media literacy, philosophical education

Niemal 120 lat temu przesłany przez Guglielmo Marconiego sygnał radiowy po raz pierwszy przemierzył Atlantyk, stając się zapowiedzią nadchodzącej w kolejnym stuleciu rewolucji komunika- 
cyjnej. Wynalazek ten, podobnie jak prasa drukarska Gutenberga, miał o wiele większe znaczenie niż na początku sądzono. Jego powstanie jest bowiem cezurą przejścia gatunku ludzkiego z ery pisma w erę mediów elektronicznych. Moment ten jest o tyle ważny, że stanowi swoisty manifest inteligentnego życia na Ziemi, który zdążył przemierzyć już niemal 120 lat świetlnych przestrzeni kosmicznej docierając do ponad 500 potencjalnych układów planetarnych. Jednocześnie zawiera on $w$ sobie fundamentalną dla naszej cywilizacji charakterystykę, jaką jest mediatyzacja. Właśnie ten proces oznaczający gatunkowe zapośredniczenie poznania świata przez media sprawia, że konieczne staje się pytanie o status podstawowych kategorii poznawczych oraz o kroki, jakie należałoby poczynić $w$ przypadku ich kryzysu.

Według teoretyków komunikacji podstawową rysem współczesności jest proces mediatyzacji (ang. mediatization). Friedrich Krotz zdefiniował ją jako „(...) historyczny, trwający i długoterminowy proces, w którym pojawia się coraz więcej mediów zinstytucjonalizowanych"1. Dla niemieckiego badacza oznacza to, że "media na dłuższą metę stają się istotne $\mathrm{w}$ społecznym konstruowaniu codziennej rzeczywistości, społeczeństwa i kultury jako całości"2. To także, obok indywidualizmu, komercjalizacji i globalizacji, jeden z czterech fundamentalnych meta-procesów, które ukształtowały współczesność ${ }^{3}$ Tak pojmowaną mediatyzację rozważać będziemy dalej $w$ ramach jednego $z$ trzech paradygmatów badawczych wskazanych przez Teresę Sasińską-Klas - „media a zmiana społeczna”4.

${ }^{1}$ Ang. a historical, ongoing, long-term process in which more and more media emerge and areb institutionalized; F. Krotz, Mediatization: a concept with which to grasp media and societal change, [w:] Mediatization: Concept, Changes, Consequences, red. K. Lundby, Peter Lang, New York 2009, s. 24.

2 Ang. Media in the long run increasingly become relevent for the social construction of everyday life, society, and culture as a whole; F. Krotz, op. cit., s. 24.

${ }^{3}$ Zob. F. Krotz, Media connectivity: Concepts, conditions, and consequences, [w:] Network, Connectivity and Flow: Key concepts for Media and Cultural Studies, red. A. Hepp, F. Krotz, S. Moores, Hampton Press, New York 2008.

4 Zob. T. Sasińska-Klas, Mediatyzacja a medializacja sfery publicznej, "Zeszyty Prasoznawcze" 2014, nr 2(218), s. 164-165. 
Analizę rozpocząć należy od przyjrzenia się istocie samych mediów. Już powierzchowna obserwacja wskazuje, że media zawierają w sobie pewną fundamentalną wewnętrzną sprzeczność kwestionującą ich wiarygodność poznawczą. Przybliżają bowiem niedostępną nam rzeczywistość, dając poczucie bycia naocznymi świadkami, lecz jednocześnie oddalają nas od niej za sprawą absolutyzacji pewnego subiektywnego i partykularnego punktu widzenia. Jak wskazuje Stuart Hall, każda ludzka komunikacja obywa się za pomocą medium (w tym języka), przez co składa się z aktu kodowania będącego transpozycją subiektywnego doświadczenia podmiotu do intersubiektywnie komunikowalnej formy oraz dekodowania według określonych kulturowo reguł ${ }^{5}$. Te dwa poziomy interpretacji wraz z ograniczeniami samego kanału sprawiają, że w komunikacje za pomocą mediów wpisana jest pewna poznawcza niedoskonałość. Co się zatem stanie, gdy do owej epistemicznej niedoskonałości mediów dodamy złą wolę nadawcy przekazu? Z taką sytuacją mamy do czynienia w trwającej obecnie epoce postprawdy.

\section{Media a rzeczywistość w epoce postprawdy}

Era postprawdy to czas, w którym kłamstwo zostało przesunięte $\mathrm{z}$ kategorii społecznego tabu do roli instrumentu służącego realizowaniu własnych celów. Ralph Keyes, autor książki Era post-prawdy: nieszczerość $i$ oszustwo we współczesnym życiu uważa, że przyczyną tego zjawiska jest brak dostrzegalnych powodów, które powstrzymywałyby przed kłamaniem oraz nieobecność ryzyka jakie niesie za sobą kłamstwo 6 . Społeczeństwo ery post-prawdy cechuje „zagubienie piętna, jakim wcześniej obarczano kłamstwo. (...) Kłamanie

${ }^{5}$ Zob. S. Hall, Encoding/decoding, [w:] Culture, Media, Language. Working Papers in Cultural Studies 1972-1979, Centre for Contemporary Cultural Studies, Routledge, London 1980, s. 128-138.

${ }^{6}$ Ł. Pawłowski, Gdzie podziała sie prawda?, „Kultura Liberalna”, 29.11.2016, https:// kulturaliberalna.pl/2016/11/29/pawlowski-post-prawda-ralph-keyes [dostęp: 11.08.2018]. 
stało się w zasadzie wykroczeniem, za które nie sposób kogokolwiek obwiniać" 7 .

Powyższa sytuacja sprawia, że żyjemy w stanie nieustannej hipokryzji elit politycznych, które traktują media jako rozlegle pole wojny dezinformacyjnej. Stan ten ułatwia fakt, że - jak zauważył Stuart Hall - owe elity, posiadając uprzywilejowany dostęp do mediów, narzucają dziennikarzom tzw. „pierwszą definicję" poruszanych problemów, której ci pozostają "więźniami”8. Jest to o tyle łatwe, że - jak wskazują liczne badania- istnieją wyraźne powiązania mediów głównego nurtu z ośrodkami władzy, które uniemożliwia im zachowanie obiektywizmu ${ }^{9}$. W efekcie mamy do czynienia z hegemoniczną reprodukcją dyskursu.

Wielowymiarowość istniejącej w mass mediach manipulacji wyczerpująco ukazuje sześć metafor Denisa McQuaila10. „Media jako okno", przez które odbiorcy postrzegają rzeczywistość, jest zawsze oknem zwróconym w którąśs stronę. Z kolei „media jako zwierciadło" odbija to, co chcą jego dysponenci. Podobnie „media jako filtr”, czyli selektywnie dobrane przekazu oraz „media jako ekran lub bariera”, które oddzielają odbiorcę od tego co rzeczywiste (ang. gatekeeping). „Media jako drogowskaz” prowadzą zawsze do pewnej z góry założonej konkluzji, zaś „media jako forum lub scena” to przestrzeń, w której ścierać się mają jedynie wybrane opinie i idee, reprezentowane przez wybrane osoby.

Takie funkcjonowanie mediów prowadzi do wysoce niepokojącej konkluzji, że rzeczywistość, którą znamy z medialnego przeka$z u$, jest wykreowanym na potrzeby polityczne (ale także rynkowe) spektaklem, który składa się z półprawd, nadinterpretacji i kłamstw.

7 Ibidem.

8 S. Hall, Policing the Crisis. Mugging, the State and Law and Order, MacMillan, London 1978; cyt. za: E. Maigret, Socjologia komunikacji i mediów, przekł. I. Piechnik, Oficyna Naukowa, Warszawa 2012, s. 265.

${ }^{9}$ E. Maigret, Socjologia komunikacji i mediów, przekł. I. Piechnik, Oficyna Naukowa, Warszawa 2012, s. 264.

${ }^{10}$ D. McQuail, McQuails's Mass Communication Theory, Sage Publications, London 2010, s. 84 . 
Spektaklem, który w opinii teoretyka polityki Sheldona Wolina jest elementem istniejące dziś w USA demokracji kierowanej (ang. guided democracy), będącej formą totalitaryzmu w nowej odsłonie tzw. „totalitaryzmu odwróconego" (ang. inverted totalitarianism) ${ }^{11}$. W efekcie doprowadziło to do erozji zaufania wobec klasy politycznej, a także instytucji odpowiedzialnych za "produkcje prawdy” - jak instytucje akademickie, grona eksperckie czy media ${ }^{12}$.

Pojawienie się nowych mediów stworzyło szansę na restytucje prawdy jako wartość w życiu publicznym. Sieć jako zdecentralizowane źródło opinii o nieograniczonym pluralizmie pozwolić miała na przełamanie monopolu informacyjnego tradycyjnych mediów. Zwłaszcza, że aksjologiczny rodowód internetu wywodzi się z etosów akademickiego i hakerskiego. Zrywy obywatelskie ostatnich dekad, które wychodząc od komunikacji elektronicznej, przekształciły się $\mathrm{w}$ aktywność polityczną $\mathrm{w}$ realnym świecie, wydawały się realizować te nadzieje. Taki wymiar miały wybory prezydenckie w Korei Południowej w 2002 r., arabska wiosna w 2011 r. czy protesty przeciw wprowadzeniu umowy ACTA w 2012 r. Jak podkreśla Manuel Castells, istniejąca poza kontrolą państwową oraz odznacza się interaktywnością przestrzeń dialogu jaką jest sieć nabrała kluczowego znaczenia dla społecznego oporu wobec wszelkich form niesprawiedliwości ${ }^{13}$.

Jednak postprawda uobecniła się również $\mathrm{w}$ nowych mediach. Wirtualną przestrzeń tworzą dziś komercyjne węzły komunikacyjne, które kapitalizują wiedzę o milionach swoich użytkowników. Platformy te umożliwiają tworzenie spersonalizowanych przekazów, które konstruują rzeczywistość „szytą na miarę” konkretnego odbiorcy, by tym sposobem wpłynąć na jego decyzje zakupowe, a coraz częściej także na decyzje polityczne. Właśnie ta strategia

11 Zob. S. Wolin, Democracy Incorporated: Managed Democracy and the Specter of Inverted Totalitarianism, Princeton Univeristy Press, Princeton 2008.

12 Yes, I'd lie to you. The post-truth world, "The Economist", 10.09.2016, https:/ / www. economist.com/briefing/2016/09/10/yes-id-lie-to-you [dostęp: 11.08.2018].

${ }_{13}$ M. Castells, Mobile Communication adn Society. A Global Perspective, MIT Press, Cambridge 2006, s. 211. 
przyczynić się miała do sukcesu wyborczego Donalda Trumpa i późniejszego skandalu z udziałem firmy analitycznej Cambridge Analytica oraz portalu Facebook ${ }^{14}$.

Tak spersonalizowana wirtualna przestrzeń prowadzi do postania tzw. bańki filtrującej, w której użytkownik ogląda rzeczywistość zgodną ze swoimi preferencjami. Coraz częściej wśród treści wypełniających ową bańkę znajdują się przekazy z gruntu fałszywe „wiadomości” - fake news, które w znacznym stopniu tworzone są przez sztuczną inteligencje. Szacuje się, iż co piąty komunikat w sieciach społecznościowych Twitter i Facebook podczas ostatnich wyborów USA był wygenerowany przez boty ${ }^{15}$. Dla Ralpha Keyesa to przede wszystkim efekt anonimowości sieci, która tworzy żyzny grunt dla rozwoju kultury oszustwa i nieszczerości ${ }^{16}$.

Jednak owa bańka nie jest efektem li tylko wyselekcjonowanego doboru treści przez algorytmy. W serwisach internetowych stosuje się wyrafinowany mechanizm cenzury zwany „ukrytym banowaniem" (ang. stelth banning). Polega ono na blokowaniu dodanych przez użytkownika treści w taki sposób, że nie wie on o istniejącej w systemie blokadzie. Jak wskazują dowody, mechanizm był stosowany m.in. przez portale Twitter i Instagram ${ }^{17}$. Jednak z uwagi na techniczną trudność wykrycia i udowodnienia jego wykorzystywania, skala jego użycia może być zdecydowanie większa.

${ }_{14}$ M. Rosenberg, N. Confessore, C. Cadwalladr, How Trump Consultants Exploited the Facebook Data of Millions, "New York Times”, 17.03.2018. https://www.nytimes. com/2018/03/17/us/politics/cambridge-analytica-trump-campaign.html [dostęp: 11.08.2018].

${ }_{15}$ M. Czarnecki, Co piatego tweeta o wyborach w USA stworzył bot. Fałszywe newsy zalały Facebooka. Jak media społecznościowe wptynęty na kampanię, "Gazeta Wyborcza”, 11.11.2016 http://wyborcza.pl/7,75248,20963144,co-piatego-tweeta-o-wyborach-wusa-stworzyl-bot-falszywe-wsy.html [dostęp: 11.08.2018].

16 Ł. Pawłowski, Gdzie podziała się prawda?, „Kultura Liberalna”, 29.11.2016, https:/ / kulturaliberalna.pl/2016/11/29/pawlowski-post-prawda-ralph-keyes [dostęp: 11.08.2018].

17 A. Ohlheiser, jnmhkl, „Washington Post”, 30.10.2015, https://www.washington post.com/news/the-intersect/wp/2015/10/30/a-guide-to-why-some-activists-belie ve-their-tweets-are-being-censored-in-the-u-s [dostęp: 11.08.2018]. 
Co więcej, anonimowość zestawiona z łatwością bycia twórcą przekazu sprawia, że internet obfituje dziś w liczne pseudonaukowe i kontrnaukowe teorie i opinie, wynikające nie tyle ze złej woli nadawców, ile z ich ignorancji. Prowadzi to do dalszego rozmycia granicy między prawdą i fałszem, tym co rzeczywiste i wymyślone.

Nawiązując do francuskiego teoretyka mediów Jeana Baudrillarda, można stwierdzić, iż media elektroniczne zabiły rzeczywistość, a z punktu widzenia epistemologicznego jest to zbrodnia doskonała, gdyż jako społeczeństwo nie mamy świadomości istnienia medialnego symulakru na jej miejscu ${ }^{18}$. Konkluzję tę należałoby jednak doprecyzować. W czasach nowych mediów i zindywidualizowanych baniek filtrujących mamy do czynienia nie z jednym, a $\mathrm{z}$ wieloma symulakrami. Stawia to pod znakiem zapytania tzw. mądrość tłumu, który w tej sytuacji staje się coraz bardziej sfragmentaryzowany i ograniczony do grup podobnie myślących użytkowników. W efekcie mamy do czynienia z epistemiczną pułapką cyfrowych mediów, które przenoszą nas na kolejny, głębszy już poziomu platońskiej jaskini, oddalając coraz dalej od tego co prawdziwe. Zwłaszcza że jednostki tworzące ów tłum są już produktem nowej, post-piśmiennej epoki, w której logos wydaje się ponownie ustępować mythosowi.

\section{Poznawcze horyzonty człowieka nowej oralności}

Za sprawą rewolucji ICT wracamy dziś do kultury oralnej, która kształtowała Homo sapiens przez setki tysięcy lat. Tym razem jednak oralności globalnej, zapośredniczonej przez media audiowizualne. Dzięki możliwościom technicznym kolejne obszary naszej codzienności stają się jej częścią. Głosowe sterowanie komputerem czy wirtualni asystenci, z którymi możemy porozmawiać, to tylko nieliczne przykłady, które uświadamiają, że cyfrowy świat już niebawem nie

${ }^{18}$ Zob. J. Boudrillard, Zbrodnia doskonała, przeł. S. Królak, Wydawnictwo Sic!, Warszawa 2008. 
będzie wymagał od nas żadnych specjalnych kompetencji poza sprawną mową. W opinii Waltera Onga „Tę nową oralność cechuje uderzające podobieństwo do tej dawnej - np. mistyka uczestnictwa, karmienie poczucia wspólnoty, skupienie na chwili bieżącej, a nawet używanie formuł"19. Eksplozja amatorskiej twórczości wideo, masowe rozpowszechnienie technologii streamingu (transmisji na żywo) czy sieciowe wspólnoty są tego najlepszymi przykładami. Ta nowa oralność zasadniczo różni się jednak od swojej pierwotnej formy. Jak wskazuje Malwina Rolka, wielowiekowe panowanie pisma i druku odcisnęło na człowieku swój ślad utrwalając w nim struktury kategoryzacji podmiotowo-przedmiotowej mających swe źródło w naukowych i filozoficznych schematach postrzegania świata ${ }^{20}$. Pismo zostawiło $\mathrm{w}$ nas swój logos, który wynika $\mathrm{z}$ jego mocy oddziaływania na psychikę. Jeżeli zatem jak dostrzega Jerzy Bobryk,

rozwój społeczny i intelektualny miałby polegać na nabieraniu dystansu do siebie, jeżeli cechą rozwiniętej osobowości jest to, że „sama dla siebie jest obiektem", to posługiwanie się tekstem niewątpliwie jest wzorem i okazją do uczenia się "postawy innego" wobec siebie samego ${ }^{21}$.

Jednak logos wypracowany przez pismo coraz bardziej kruszeje wraz z dominacją środków audiowizualnych. Najbardziej symptomatyczną tego oznaką jest globalny spadek czytelnictwa, który zaobserwować można tak w prasie, jak i literaturze. Czołowe tytuły próbują ratować się, tworząc ofertę audiowizualną coraz bardziej opartą o łatwo przyswajalne treści wideo i telewizje internetowe. Z kolei na liście bestsellerów książkowych królują dziś pozycje literatury rozrywkowej, a sprzedaż pozycji ambitnych jest znikoma. Trudno nie połączyć powyższego zjawiska z pojawieniem się anal-

${ }^{19}$ W.J. Ong, Oralność i piśmienność. Stowo poddane technologii, przeł. J. Japola, Warszawa 2011, WUW, s. 205.

${ }^{20}$ M. Rolka, Mit i oralność w świetle diagnoz kryzysu kultury nowoczesnej, „Hybris” 2016, nr 34, s. 120.

${ }^{21}$ J. Bobryk, Spadkobiercy Teuta. Ludzie i media, Wydawnictwo Uniwersytetu Warszawskiego, Warszawa 2001, s. 6. 
fabetyzmu funkcjonalnego. Tylko z badań Biblioteki Narodowej z 2016 r. wynika, że 63\% Polaków w ogóle nie czyta książek²2. A jak zauważa Zbigniew Kwieciński z UMK, nierozumienie czytanego tekstu to problem $70 \%$ społeczeństwa, w tym co szóstego magistra ${ }^{23}$.

Innym niepokojącym procesem jest ubożenie języka, tak mówionego, jak i pisanego. $\mathrm{W}$ pewnej mierze jest to konsekwencja wskazanego zaniku czytelnictwa. Jednak na stan ten wpływ maja również inne przyczyny. $Z$ jednej strony są to technologie komunikacyjne, które wymuszają rezygnację z zasad poprawności językowej na rzecz szybkości przekazu informacji. Z drugiej kondycja kultury popularnej, która w wyniku sprowadzania treści do wspólnego mianownika uległa znacznej banalizacji.

Ten zwrot do banału wydaje się być konsekwencją panowania zasady przyjemności. To główna zasada kultury analgetyku, kultury znieczulenia, o której pisał w Obecności Mitu Leszek Kołakowski²4. Za pomocą bogatej oferty rozrywkowej, zwłaszcza audiowizualnej oraz niemal nieskończonej oferty dóbr, zamyka się sens ludzkiego życia w akcie konsumpcji, przez co pozostaje on znieczulony na wszelkie egzystencjalne dylematy.

Świat człowieka post-piśmiennego wydaje się zatem ukształtowany bardziej przez afektywności niż racjonalność. Nabożnie oddając się konsumpcji, nie ma on już ani czasu, ani ochoty, ani kompetencji, by krytycznie odnieść się do otaczającej go rzeczywistości.

Wraz z ubożeniem języka, którego granice - jak stwierdził Ludwik Wittgenstein w swym słynnym Traktacie - wyznaczają granice naszego świata, zmniejsza się potencjał emancypacyjny jednostek. $\mathrm{W}$ tej sytuacji wyjście z epistemicznej pułapki cyfrowych mediów

22 M. Widła, Grozi nam wtórny analfabetyzm? Polacy czytają coraz mniej, „Newsweek", 11.03.2016, http:/ / www.newsweek.pl/polska/grozi-nam-wtorny-analfabe tyzm-polacy-czytaja-coraz-mniej,artykuly,381658,1.html [dostęp: 11.08.2018].

${ }_{23}$ M.J., Nie rozumiemy informacji, instrukcji, ulotek. Kwitnie analfabetyzm wtórny, „Nowa Trybuna Opolska”, 8.09.2011, http://www.nto.pl/wiadomosci/opolskie/art/ 4452107,nie-rozumiemy-informacji-instrukcji-ulotek-kwitnie-analfabetyzm-wtorny, id,t.html [dostęp: 11.08.2018].

24 Zob. L. Kołakowski, Obecność mitu, Prószyński i S-ka, Warszawa 2003. 
wydaje się niemal niemożliwe. Za Edwinem Bendykiem zapytajmy: "Czy jednak można jeszcze odzyskać rozum w przestrzeni publicznej czy już pozostało jedynie czekać na demony?" 25 .

\section{Analogowe remedium ma epistemiczną pułapkę cyfrowych mediów}

Wobec tak naświetlonej sytuacji konieczne wydają się odpowiednie działania edukacyjne. $W$ tym zakresie proponuje się przede wszystkim edukację medialną, która poprzez wykształcenie odpowiednich umiejętności i kompetencji prowadzić ma do osiągnięcia „medialnej piśmienności” (ang. media literacy), koniecznej by stać się autonomiczną i świadomą jednostką w nowym, cyfrowym środowisku komunikacyjnym ${ }^{26}$. Jej modele obejmują najczęściej: 1) krytyczną analizę mediów i tekstów medialnych, 2) kompetencje w posługiwaniu się mediami i tworzeniu przekazów medialnych, 3) wiedzę o zagrożeniach wynikających z korzystania z mediów i sposobach ich uniknięcia.

W kontekście tytułowego problemu najważniejszy wydaje się obszar krytycznej analizy (ang. digital critical literacy). W istocie obszar ten, pytając o "prawdę tekstu” medialnego i mechanizmy funkcjonowania medialnej infosfery, jest wycinkiem szerszego pola refleksji, które uznać można za bardziej uniwersalne i podstawowe - filozofii. Ta, oferując najszerszy z możliwych punktów widzenia oraz ponadczasowo aktualne "analogowe" kompetencje, okazuje się stanowić idealne dopełnienie edukacji medialnej.

25 E. Bendyk, Dyktatura kłamstwa, polityka i post-prawda, https://antymatrix.blog.po lityka.pl/2016/09/10/dyktatura-klamstwa-polityka-i-post-prawda/ [dostęp: 11.08. 2018].

26 P. Tornero, J. Manuel, Study of the Current Trends and Approaches on Media Literacy in Europe, European Commision 2007, s. 10, http:/ /www.gabinetecomunica cionyeducacion.com/sites/default/files/field/adjuntos/study_media_literacy_in_ europe_0.pdf [dostęp: 11.08.2018]. 
Jak wskazują doświadczenia pedagogów, nauczanie filozofii rozwija wiele istotnych z punktu widzenia współczesności kompetencji. Dostrzega się, że filozofia kształtuje umiejętność krytycznego, logicznego i twórczego myślenia ${ }^{27}$. Kształci także samodzielność myślenia, lepsze rozumienie świata, ludzi i samego siebie, a także uwrażliwia moralnie. Cieszy zatem fakt, że 30 stycznia 2018 r. Minister Edukacji Narodowej Anna Zalewska podpisała rozporządzenie w sprawie podstawy programowej kształcenia ogólnego, na mocy którego do oferty edukacyjnej szkół ponadpodstawowych zostanie wprowadzona filozofia ${ }^{28}$. Wcześniej rzadko kiedy pojawiała się w szkolnym programie nauczania. W 2014 r. na ponad 14 tys. placówek nauczano jej jedynie w 214 placówkach, w tym jedynie w 18 w zakresie rozszerzonym ( 240 godzin ${ }^{29}$.

Przeglądając podstawę programową kształcenia ogólnego szkoły średniej, zauważyć można, że w wymiarze podstawowym stanowi ona jedynie historię filozofii starożytnej, co czyni ją mało użyteczną z punktu widzenia budowania krytycznej jednostki. Zdecydowanie lepiej prezentuje się podstawa rozszerzona. Obejmuje bowiem trzy uzupełniające się bloki:

1) kulturę logiczną (I) - elementy semiotyki i teorii argumentacji,

2) elementy historii filozofii (II) o nachyleniu kulturoznawczym historia filozofii uwzględniająca przede wszystkim myślicieli lub prądy filozoficzne,

3) wybrane problemy filozofii (III) - wprowadzenie do głównych zagadnień, pojęć i stanowisk filozoficznych ${ }^{30}$.

27 Po co w szkole filozofia?, Portal Instytutu Badań Edukacyjnych, 18.06.2015, http:/ / www.ibe.edu.pl/pl/biblioteka/11-media/aktualnosci-prasowe/498-po-co-wszkole-filozofia [dostęp: 11.08.2018].

28 Podstawa programowa z filozofii i etyki dla szkót ponadpodstawowych, Portal Filozofuj, http:/ / filozofuj.eu/podstawa-programowa-filozofii-etyki-dla-szkol-ponadpod stawowych-podpisana [dostęp: 11.08.2018].

${ }^{29}$ Nauczanie filozofii na III i IV etapie edukacyjnym, Instytut Badań Edukacyjnych, Warszawa 2015, s. 3, http://eduentuzjasci.pl/images/stories/publikacje/ibe-raportnauczanie-filozofii.pdf [dostęp: 11.08.2018].

30 Podstawa programowa kształcenia ogólnego dla czteroletniego liceum ogólnokształcacego i pięcioletniego technikum z przedmiotu filozofia, http://filozofuj.eu/wp-content/ uploads/2018/02/podstawa-programowa-z-filozofii.pdf [dostęp: 11.08.2018]. 
Zastanawiając się nad najlepszym modelem nauczania filozofii, który wespół $\mathrm{z}$ edukacją medialną stanowić miałby remedium na epistemiczną pułapkę cyfrowych mediów, należy zauważyć, że powyższy rozszerzony zakres kształcenia filozoficznego wymagałby pewnego uzupełnia oraz właściwego rozłożenia akcentów.

Niezwykle potrzebny i właściwy jest blok pierwszy: kultura logiczna obejmujący elementy semiotyki i teorii argumentacji. W przekazie medialnym często dochodzi bowiem do nadużyć nie tylko w warstwie obrazu, ale też na poziomie języka, podczas wnioskowania i argumentowania. $\mathrm{W}$ rezultacie niewprawieni $\mathrm{w}$ chwyty retoryczne i sztukę manipulowania logiką wywodu widzowie dają się zwieść takiemu sofistycznemu przekazowi. Dlatego erystyka, a więc sztuka prowadzenia sporów, powinna stanowić również element treningu filozoficznego. Fakt ten został dostrzeżony przez inicjatorów projektów „Filozofia w akcji” i „Filozofia na co dzien", w których erystyka stanowiła część programu nauczania ${ }^{31}$.

Jednak najistotniejszy wydaje się obszar kształcenia filozoficznego obejmujący główne zagadnienia, pojęcia i stanowiska filozoficzne. W kontekście postawionego problemu wydaje się właściwe, by koncentrował się on na zagadnieniach epistemologicznych pytających o warunki poznania i to, co jest poznawane. Poza tekstami klasyków filozofii moduł ten powinien przybliżać zwłaszcza współczesną refleksję z pola filozofii mediów, medioznawstwa i filozofii techniki. Są to bowiem przenikające się dyscypliny, które razem pozwalają uchwycić modus operandi stechnicyzowanego i zmediatyzowanego świata.

W sytuacji kryzysu zaufania do instytucji wytwarzających wiedzę - nauki, istotne byłoby również ukazanie jej metodologicznych i społecznych podstaw. W tym zakresie niezastąpiona jest filozofia nauki, która ukazuje podstawowe metody i mechanizmy dochodzenia nauki do wiarygodnego poznania, a także jej społeczne uwarunkowania.

${ }^{31}$ Filozofia w szkołach, Portal Uniwersytetu Warszawskiego, https://www.uw. edu.pl/filozofia-w-szkolach [dostęp: 11.08.2018]. 
Ważną składową procesu kształcenia winna być także krytyczna analiza szeroko rozumianych tekstów kultury. Teksty pisane, werbalne, audiowizualne stanowią bowiem nośniki społecznych dyskursów leżących u podstaw świadomości społecznej. Ich krytyczna analiza, zwłaszcza w zakresie konsumowanych masowo przez młodzież amatorskich produkcji wideo, seriali i gier komputerowych, pozwoliłaby dostrzec jakich wartości, ideologii czy postaw są one nośnikami, a w efekcie jaką rzeczywistość modelują. Jednocześnie zaszczepiałoby to krytyczną postawę cechującą się programową nieufnością wobec wszelkich tekstów kultury, zwłaszcza kultury masowej.

Wszystkie z powyższych obszarów przenikać musiałby etyczny imperatyw wychowania do wartości, jaką jest prawda, wiążący ją ze społeczną odpowiedzialnością jednostki oraz troską o dobro wspólne.

Kształcenie filozoficzne $\mathrm{w}$ zaproponowanym kształcie, a wiec oparte o kulturę logiczną i erystykę, akcentujące zagadnienia epistemologiczne w kontekście funkcjonowania mediów, ukazująca działanie nauki, krytycznie analizujące dyskursy tkwiące w tekstach audiowizualnych oraz wychowujące do wartości wydaje się koniecznością naszych czasów. Realizowane masowo w systemie oświaty i kontynuowane na etapie szkolnictwa wyższego mogłyby w znacznym stopniu przyczynić się do przywrócenia rozum w przestrzeni publicznej i tym samym wyrwać nas z epistemicznej pułapki cyfrowych mediów. Ale na tak ekstensywną ich obecność w nakreślonym kształcie przyjdzie nam z pewnością jeszcze długo poczekać.

\section{Bibliografia}

Bendyk E., Dyktatura kłamstwa, polityka i post-prawda, https://antymatrix.blog.poli tyka.pl/2016/09/10/dyktatura-klamstwa-polityka-i-post-prawda/ [dostęp: 11.08. 2018].

Bobryk J., Spadkobiercy Teuta. Ludzie i media, Wydawnictwo Uniwersytetu Warszawskiego, Warszawa 2001.

Boudrillard J., Zbrodnia doskonała, przeł. S. Królak, Wydawnictwo Sic!, Warszawa 2008. 
Castells M., Mobile Communication adn Society. A Global Perspective, MIT Press, Cambridge 2006.

Czarnecki M., Co piatego tweeta o wyborach w USA stworzyt bot. Fałszywe newsy zalaty Facebooka. Jak media społecznościowe wptynęty na kampanię, "Gazeta Wyborcza”, 11.11.2016 http://wyborcza.pl/7,75248,20963144,co-piatego-tweeta-o-wyborachw-usa-stworzyl-bot-falszywe-wsy.html [dostęp: 11.08.2018].

Kołakowski L., Obecność mitu, Prószyński i S-ka, Warszawa 2003.

Krotz F., Mediatization: a concept with which to grasp media and societal change, [w:] Mediatization: Concept, Changes, Consequences, red. K. Lundby, Peter Lang, New York 2009.

Krotz F., Media connectivity: Concepts, conditions, and consequences, [w:] Network, Connectivity and Flow: Key concepts for Media and Cultural Studies, red. A. Hepp, F. Krotz, S. Moores, Hampton Press, New York 2008.

Nauczanie filozofii na III i IV etapie edukacyjnym, Instytut Badań Edukacyjnych, Warszawa 2015, http://eduentuzjasci.pl/images/stories/publikacje/ibe-raport-nau czanie-filozofii.pdf [dostęp: 11.08.2018].

Nie rozumiemy informacji, instrukcji, ulotek. Kwitnie analfabetyzm wtórny, "Nowa trybuna opolska", 8.09.2011, http://www.nto.pl/wiadomosci/opolskie/art/4452 107,nie-rozumiemy-informacji-instrukcji-ulotek-kwitnie-analfabetyzm-wtorny, id,t.html [dostęp: 11.08.2018].

Maigret E., Socjologia komunikacji i mediów, przekł. I. Piechnik, Oficyna Naukowa, Warszawa 2012.

McQuail D., McQuails's Mass Communication Theory, Sage Publications, London 2010.

Ohlheiser A., Tweets are disappearing on Twitter. Why?, "Washington Post", 30.10.2015, https://www.washingtonpost.com/news/the-intersect/wp/2015/ 10/30/a-guide-to-why-some-activists-believe-their-tweets-are-being-censoredin-the-u-s [dostęp: 11.08.2018].

Ong W. J., Oralność i piśmienność. Słowo poddane technologii, przeł. J. Japola, WUW, Warszawa 2011.

Pawłowski Ł., Gdzie podziała się prawda?, „Kultura Liberalna”, 29.11.2016, https:// kulturaliberalna.pl/2016/11/29/pawlowski-post-prawda-ralph-keyes [dostęp: 11.08.2018].

Po co w szkole filozofia?, Portal Instytutu Badań Edukacyjnych, 18.6.2015, http:/ / www. ibe.edu.pl/pl/biblioteka/11-media/aktualnosci-prasowe/498-po-co-w-szkolefilozofia [dostęp: 11.08.2018].

Podstawa programowa kształcenia ogólnego dla czteroletniego liceum ogólnoksztatcacego i pięcioletniego technikum z przedmiotu filozofia, http://filozofuj.eu/wp-content/ uploads/2018/02/podstawa-programowa-z-filozofii.pdf [dostęp: 11.08.2018].

Podstawa programowa z filozofii $i$ etyki dla szkót ponadpodstawowych, Portal Filozofuj, http:/ / filozofuj.eu/podstawa-programowa-filozofii-etyki-dla-szkol-ponadpod stawowych-podpisana [dostęp: 11.08.2018]. 
Rolka M., Mit i oralność w świetle diagnoz kryzysu kultury nowoczesnej, „Hybris” 2016, nr 34, s. 119-136.

Rosenberg M., Confessore N., Cadwalladr C., How Trump Consultants Exploited the Facebook Data of Millions, „New York Times”, 17.03.2018, https:/ / www.nytimes. com/2018/03/17/us/politics/cambridge-analytica-trump-campaign.html [dostęp: 11.08.2018].

Sasińska-Klas T., Mediatyzacja a medializacja sfery publicznej, "Zeszyty prasoznawcze” 2014, nr 2 (218), s. 162-175.

Tornero P., Manuel J., Study of the Current Trends and Approaches on Media Literacy in Europe, European Commision, 2007, http://www.gabinetecomunicacionyeduca cion.com/sites/default/files/field/adjuntos/study_media_literacy_in_europe _0.pdf [dostęp: 11.08.2018].

Widła M., Grozi nam wtórny analfabetyzm? Polacy czytają coraz mniej, "Newsweek”, 11.03.2016, http:/ / www.newsweek.pl/polska/grozi-nam-wtorny-analfabetyzmpolacy-czytaja-coraz-mniej,artykuly,381658,1.html [dostęp: 11.08.2018].

Wolin S., Democracy Incorporated: Managed Democracy and the Specter of Inverted Totalitarianism, Princeton Univeristy Press, United States 2008.

Yes, I'd lie to you. The post-truth world, "The Economist”, 10.09.2016 https://www. economist.com/briefing/2016/09/10/yes-id-lie-to-you [dostęp: 11.08.2018]. 